\title{
SERVICE REGULATIONS FOR ELECTRICAL UTILITIES
}

\author{
By L. H. HARRIS,
}

Associate Professor of Electrical Engineering, University of Pittsburgh.

It is the purpose of this article to present, in condensed form, some of the present day conditions in the field occupied by the electrical utilities, and to outline briefly what principles should govern the formation of the rules of a public service commission pertaining to such utilities. Underlying all rules must be the fundamental principle of fair play - a just return to the public in the form of safe and adequate service on the one hand, and a fair compensation to the utility for the service demanded, on the other.

Many difficulties are to be met with in attempting the solution of this problem. The standards of service must be higher under some conditions than others. Care must be exercised that the utilities are not compelled to supply, and the communities to pay for, a quality of service not commensurate with their needs. The development of small and outlying districts should not be retarded by prohibitive rates. Rules must be so worded that they can be observed and yet not appear to give official sanction to a lowering of the standards of service. It is very difficult in many cases to draw the line between the end sought and the means to that end. The rules should unquestionably set the standards and wherever possible should define satisfactory service, but under no avoidable circumstances should they prescribe methods of management unless absolutely essential to secure the desired results. Every possible freedom should be given to the management not positively inimical to the carrying out of the service requirements.

Full use should be made of the state association where such an organization exists, and of the National Electrical Light Association. Credit should be given to the work of these bodies and wherever possible the standards of service, the methods of procedure, and all requirements should be in accord with those which have received the approval of these associations. The influence which such organizations can and do bring to bear on men engaged in the same line of work are fully as effective as any pressure from without, and should be encouraged to the fullest extent. 
Too much importance cannot be attached to the value of the good will and coöperation of the utilities themselves. Much can be done to disarm the rather natural suspicion and gain the confidence of the men representing the utilities by the exercise of tact and by giving due consideration to the opinions of these men who have spent years in the work. Once they are convinced that a commission is disposed to be perfectly fair; that it is as ready to protect a utility from an unreasonable public as to protect a public from an unreasonable utility, one of the greatest barriers to satisfactory regulation is removed. The existence of a commission of the proper character should give stability to the industry and peace of mind to the conscientious management. Few men in responsible positions prefer to give poor service. Competition and the fear of competition are as often the cause of low quality as they are of low prices.

In the effort to follow standard practices, considerable care should be taken that the rules of other commissions are not followed blindly. Every state presents some peculiar conditions that deserve consideration. A prairie state which has no water power, no cheap fuel, which is essentially an agricultural district with few if any large cities, certainly differs from one with large urban centers, which abounds in natural resources, and which possesses many large isolated power users.

Summarizing briefly, then, it seems that the principles that should in some measure govern the formation of the rules are:

1. There should be as few rules as possible.

2. They should deal only with such things as are pertinent to the rendering of good service.

3. They should be of such character that they can be observed by every well intentioned company.

4. They should be worded in the simplest and most direct language, even if this robs them entirely of their legal aspect.

5. They should disturb established business routine as little as possible, and should require just as little additional work and expense as will insure the successful operation of the rule.

6. They should, in so far as possible, conform to the recommendations of the state and national societies working to the same end, and should encourage coopperation from these bodies.

7. They should carefully distinguish between the object of the rule and the means necessary to secure that object, and should religiously avoid inf ringement on the field of the manager.

8. They should encourage rather than discourage the development of the industry. 
In the following it is assumed that a commission is concerned only with those things that go to make up the quality of the service rendered to the public. No effort is here made to formulate definite rules, but rather to discuss briefly the general nature and limitations of such rules as are intended to control directly the eloments of service. These elements are:

a. Continuity. This is without question the most important. No human agency, much less a mere rule, can insure it. In a system covering miles of territory and with a dozen different links in the chain, many things can happen that will interrupt the service on all or a portion of the system, and which cannot by any chance be foreseen. There are, however, two precautionary measures which should be adopted and rigidly enforced, and which will greatly reduce the likelihood of interruptions. One is to require the utilities to make thorough, systematic, and periodic inspections of all the various links where prevention is possible. The second is to require a detailed record of all such interruptions. The first, if properly done, will greatly reduce the preventable accidents, while the second will furnish the moral stimulus conducive to sustained and wholehearted effort for the elimination of such occurrences.

b. Constancy of Voltage. In almost all classes of service this will rank second in importance. This can best be discussed under the two sub-heads, lighting and power. In lighting, particularly, the question of permissible variation in voltage is complicated by the fact that not only the magnitude of the variation, but also the duration and the frequency with which variations occur, are of importance. The voltage on a house lighting circuit may drop, momentarily, 10 per cent or more below the normal, and, if this happens but rarely, cause nothing more serious than curiosity; or the voltage may vary 4 or 5 per cent above or below normal, and if the change take place gradually, be scarcely noticed. If, however, a variation of so little as 1 per cent occur at the critical frequency, say once every second, it may become a very serious matter.

For power circuits the same change in voltage is not so serious, though wide variations in the voltage of alternating current circuits cause considerable change in the speed of induction motors, and in the heating of all induction apparatus. Direct current power circuits should meet about the same requirements as alternating current circuits, except possibly the rare instances where power is sold from 
direct current trolley wires, in which case they should be exempt from specified voltage regulations.

There are two ways of covering the matter. One is by a rule setting definite limits beyond which no utility should permit its fluctuations in voltage to extend. This has the disadvantage that it is difficult to set limits wide enough so that they can in all cases be met, and yet not appear to give official sanction to a quality of service poorer than the public is used to and has a right to demand. Where the rule takes this form the permissible limit should be set at about 5 per cent above or below the normal voltage, and such wide variations should be permitted to occur but seldom and then only gradually. Even with this limited range, the lamps, if rated at the normal voltage of the circuit, will be subject to changes in life and candle power of approximately 20 per cent above and below normal life and candle power. The permissible variation on power circuits could justly be double that named above. The other form of the rule would simply indicate what variations would ordinarily be allowed, or considered reasonable service, and leave all questions pertaining to such cases as actually do constitute poor service for adjustment in the individual cases. This would permit the setting of higher standards, say a maximum permissible variation of 3 . per cent above and below normal for lighting circuits and double this for power circuits. In any case each utility should adopt standard service voltages for the different centers, or districts, or zones, and should provide every reasonable facility for maintaining the voltage practically constant at all times during which service is supplied.

c. Variations in Frequency. Such variations in frequency as are likely to occur in practice are not objectionable on lighting circuits. They might become so on power circuits due to the change in the speed of alternating current motors and the increased heating in induction apparatus on frequencies lower than normal. A 5 per cent variation either way should be sufficient.

d. Meters. At no other point does the utility meet so intimately such a large portion of its public as at the meters. The meter is the ever-present agent of the company, and upon its integrity depends to a large extent the reputation of its owner. No management which values the good will of its patrons can afford to have its meters fast, neither can it, in justice to its stockholders, permit meters to become slow. The rules pertaining to meters should contemplate and provide for: 
1. Periodic tests of service meters.

2. Complaint or request tests.

3. Limitations of permissible inaccuracy.

4. Specified procedure for determining the accuracy.

5. A penalty on the utility in the shape of a refund to the consumer for meters fast beyond the allowable limits.

6. Tests with and without such accessories as instrument transformers.

7. Tests at appropriate power factors, and

8. The possession by each utility of adequate and satisfactory testing facilities.

1. Periodic Tests. All service watt-hour meters should be tested periodically, preferably by the utility in their place of installation, with approved equipment, and without charge to the consumer. The length of the period between such tests may vary from three years for the modern low capacity induction type of meter to one year for the larger self-contained polyphase meters and the commutator and mercury types.

2. Complaint Tests. Every consumer should have the privilege of having his meter tested at any time that he is in doubt as to its accuracy. To prevent an aggrieved citizen from taking an unfair advantage of the utility, the consumer should be required to deposit a sum sufficient to cover the cost of making the test and which he would forfeit to the utility in case the meter was found to be correct within the established limits. In case the meter be found to be fast or slow beyond the established limits, the utility should bear the burden of making the test and the deposit returned to the consumer. The justice of this is evident when it is remembered that it is the duty of the utility to maintain its meters approximately correct.

3. Limitations of Permissible Inaccuracy. These limits are set in practice by the inherent qualities of the meters and by the economic balance between the time required to make fine adjustments and the benefits gained thereby. Meters which register from 98 to 102 per cent of the energy passing through them are usually considered correct, and no penalties should be imposed until the accuracy falls without the limits represented by 96 per cent and 104 per cent.

4. Method of Determining the Accuracy. The methods of measuring the accuracy of a meter vary, due to the difference in the definition of the expression "accuracy of the meter." The actual error of a meter depends upon the load at which it is measured, hence the necessity for the definition of the term. It is usually de- 
fined in terms of the accuracy at two or more different load points, e.g., it might be the average of the accuracy at "light load" and the accuracy at "full load" or "heavy load," these terms being defined; or it might be considered as the average of the accuracy at "light," "normal," and "heavy" loads, giving more weight to the accuracy at "normal" load. This necessitates the definition of still another term-normal load. The normal load is based upon the class of service in question and may, of course, be different from the actual normal load for a particular meter. In some cases the half load point is used for the normal load point. All are approximations and since the calibration curves for the modern meter are fairly straight, it would seem that the simplest is the best for all practical purposes.

5. Penalty for Fast Meters. There seems to be no question about the justness of making some reparation to the consumer in cases where the meter has been found to be unreasonably fast. The argument here hinges entirely on how far back the refund should go. Since experience shows that for every meter that runs fast in excess of the limit, there are about six that run slow in excess of the same limit, it would seem that the utility should not be required to make refund beyond the current bill.

6. Meters used in conjunction with instrument transformers are usually of small capacity, and are much more easily tested as selfcontained units. This should be permitted on condition that the ratios of the transformers are known. The testing of instrument transformers is not an easy matter and, wherever possible, the ratio of the manufacturer's test should be accepted. If no tests have ever been made on the transformer, it should be compared with another and calibrated transformer at least once to establish an acceptable ratio.

7. Power Factor Tests. Most modern alternating current meters are provided with an adjustable compensation for low power factors, or are adjusted for correct registration in the factory, on such low power factors. If this has not been done the meters should be tested in service for low power factor accuracy in all cases where the load is inductive.

8. Facilities for Testing. Whether the testing of service meters be done by the commission or by the utilities, the integrity of the testing apparatus should be beyond question. This duty of supervising the character of the testing facilities belongs to the state. 
As to the exact nature of these facilities, much depends upon the magnitude of the scale upon which the testing must be done. For service meters the rotating standards are usually best adapted, while for check meters the indicating types may be most suitable.

The last and not the least important of all the rules which are necessary is the one pertaining to the records which should be kept. This constitutes a valuable part of the work, and, while it can easily be made burdensome, yet if indulged in, in moderation and in reason, it furnishes a trustworthy guide to the activities of the utility and in many instances constitutes the only witness for the defense in cases on complaint before the commission. 